\title{
Analysis of knowledge and attitude regarding antenatal examination among nursing students in Sikkim: a descriptive co-relational study
}

\author{
Barkha Devi $^{1 *}$, Bidita Khandelwal ${ }^{2}$, Mridula Das ${ }^{1}$
}

\author{
${ }^{1}$ Sikkim Manipal College of Nursing, Sikkim Manipal University, Tadong, Gangtok, India \\ ${ }^{2}$ Department of Medicine, Sikkim Manipal Institute of Medical Sciences, Tadong, Gangtok, India
}

Received: 25 August 2016

Accepted: 24 September 2016

\author{
*Correspondence: \\ Ms. Barkha Devi, \\ E-mail: barkhadevi2@gmail.com
}

Copyright: () the author(s), publisher and licensee Medip Academy. This is an open-access article distributed under the terms of the Creative Commons Attribution Non-Commercial License, which permits unrestricted non-commercial use, distribution, and reproduction in any medium, provided the original work is properly cited.

\section{ABSTRACT}

Background: The antenatal period is a time of physical and psychological preparation of birth and parenthood. Becoming a part is a time of intense learning both for parents and those close to them. This can be a time of great hope and joyful anticipation. The primary aim of antenatal care is to achieve, at the end of pregnancy, a healthy mother and healthy baby. The quality of care is more important than the quantity. Most women pass through the period with specific assessment, supportive measures and encouragement. Life threatening conditions place the woman and fetus at risk for significant mortality and morbidity. The objective of the study was to assess the knowledge of nursing students regarding the antenatal examination and also to assess their attitude towards it at selected nursing institute of Gangtok, Sikkim. Hence the present study was planned to assess and compare the knowledge and attitude towards antenatal examination among nursing students.

Methods: A quantitative, descriptive, co-relational study was carried out at Sikkim Manipal College of Nursing, Vinayaka Mission College of Nursing and School of Nursing, STNM hospital Gangtok, Sikkim, India. Data were collected using structured questionnaire for which validity and reliability was ensured. 64 nursing students' were selected through non-probability convenience sampling technique who are currently undergoing 3rd year GNM, 1st year PBBSc and 3rd and 4th year B. Sc. Nursing programme and attended regular classes on antenatal examination.

Results: The findings revealed that nursing students had mean knowledge score of $20.07(66.97 \%)$ on antenatal examination. However, the majority of nursing students $(n=54,84.3 \%)$ did not have adequate knowledge on antenatal examination. The study revealed that nursing students had positive attitudes towards antenatal examination with mean score $75.2(89.5 \%)$ against a possible score of 84 (SD 4.098). The study also reveals that there was poorly positive relationship found between knowledge of nursing students and their attitude towards antenatal examination $(\mathrm{P}<0.05)$. Different nursing programme significantly influences knowledge regarding antenatal examination $(P=0.001)$, while attitude was influenced by number of times nursing students performed antenatal examination and total theory hours attended respectively $(\mathrm{P}<0.05)$.

Conclusions: A majority of nursing students demonstrated inadequate knowledge but had favorable attitude towards antenatal examination. As nurses are the major health care providers in community settings if their knowledge is enhanced it can contribute effectively to achieve the goal in reduction of maternal and infant mortality rate.

Keywords: Attitude, Antenatal examination, Antenatal care, Abdominal palpation, Knowledge, Nursing students

\section{INTRODUCTION}

Maternal mortality is a health indicator that shows very wide gaps between rich and poor, urban and rural areas, both between countries and within them. Although the maternal mortality ratio reduced from 212 in 2007 to 174 in 2015. Mothers in the lowest economic bracket still have about a two and a half times higher mortality rate. ${ }^{1}$ The importance of maternal health in the overall development and wellbeing of the society cannot be over 
emphasized. The crucial importance of maternal health was underscored by the 5th goal of the United Nations Millennium Development Goals which is aiming at improving maternal health. Maternal health is a basic requirement of fetal health and favourable outcome of pregnancy. $^{2}$

In India, pregnancy related deaths of women have declined over the years. The number of maternal deaths per year has come down from approximately 1, 00,000 deaths (1991-01) to 44,000 deaths in 2015. Though, more than $50 \%$ reduction has been registered in the approximate number of maternal deaths in the last two decades, the present status shows that, even now, 120 women die of causes associated with pregnancy, in a day, in India. ${ }^{3}$

The antenatal period is a time of physical and psychological preparation of birth and parenthood. Becoming a part is a time of intense learning both for parents and those close to them. Promotion of maternal and child health has been one of the most important components of the Family Welfare Program of the Government of India and the national population policy$2000 .^{4}$

The wealth of the nation is its healthy population. Today's children are tomorrow's citizen who should be healthy. The mother's contribution in creating a healthy population is beyond explanation. Hence the mother must be prepared physically, emotionally and socially to bring forth a healthy child. ${ }^{5}$

Nursing curriculum includes variety of subjects taught in each year of the course among which midwifery nursing is one of the subject to be learnt. ${ }^{6}$ Appropriate antenatal and intra-partum management is dependent on accurate assessment of in-utero fetal presentation, position and wellbeing with decisions regarding place, mode and position for delivery relying on correct assessment of fetal presentation and position. ${ }^{7}$ Students may participate in Antenatal examination in various ways they may be involved in planning, implementing, administrating or evaluating, screening and testing programme or they may educate, assist and support the pregnant women to undergo regular antenatal examinations. ${ }^{8}$

Antenatal examination is a screening procedure that should be performed at each antenatal appointment from 24 weeks to estimate fetal size and from 36 weeks gestation to assess fetal presentation. It should be performed on admission to hospital, prior to an auscultation of a fetal heart, cardiotocograph (CTG), vaginal examination (VE), prior to any intervention i.e. external cephalic version (ECV) and daily in an antenatal inpatient. Abdominal palpation can also be used as a means to assess, length, frequency and strength of uterine contractions and postnatally to gauge uterine involution. ${ }^{8}$
In healthcare system, nurses are the backbone of health care delivery system. Hence training of nursing students is important in order to acquire the necessary knowledge and attitude to provide quality obstetric care which will consequently contribute in reduction of maternal deaths. ${ }^{9}$ Thus future nurses' knowledge and attitudes towards antenatal examination is important to research and understand, especially in a country with a high prevalence of maternal death. Considering the fact that these students are young educated individuals, who can influence others' attitudes via counselling, hence this study, is designed to assess the knowledge and attitudes of these students as important sources of information. ${ }^{10}$ The authors cannot find any published studies on this topic in North eastern region of India in the databases searched.

\section{Problem statement}

Comparison of knowledge and attitude of nursing students regarding antenatal examination at selected nursing institution in Gangtok, Sikkim.

\section{Objectives}

The study aimed to

1. ASSESS the knowledge regarding antenatal examination among nursing students

2. ASSESS the attitude regarding antenatal examination among nursing students

3. IDENTIFY relationship between knowledge and attitude of nursing students regarding antenatal examination

4. FIND out the association between selected socio demographic variables with knowledge and attitude scores of nursing students regarding antenatal examination.

\section{Operational definitions}

1. Antenatal examinations: In this study it refers to abdominal examination consisting of inspection, pelvic palpation and auscultation

2. Knowledge: In this study it refers to correct response of nursing student regarding antenatal examination as measured by structured knowledge questionnaire.

3. Attitude: Attitude is described as a tendency to respond in a consistently favorable or unfavorable manner towards a specific topic, concept or idea. In this study it refers to opinion of the nursing students related to antenatal examination as measured by structured attitude scale.

\section{Hypothesis}

All hypothesis measure at 0.05 level of significance. 
$H_{1}$ : There is a significant relationship between knowledge and attitude of nursing students regarding antenatal examination.

\section{METHODS}

The purpose of this study is to assess the knowledge of nursing students regarding the performance of antenatal examination and also to assess their attitude towards antenatal examination.

This is a descriptive co-relational study carried out at Sikkim Manipal College of Nursing, Vinayaka Mission College of Nursing and School of Nursing, STNM hospital Gangtok, Sikkim, India between the period of April 2016 to July 2016 to assess the knowledge and attitude regarding antenatal examination. 64 nursing students were selected by non-probability convenience sampling technique from selected nursing institution of Sikkim. The inclusion criteria for sample was nursing students who are currently enrolled in $1^{\text {st }}$ year PBBSc Nursing, $3^{\text {rd }}$ year and 4th year B.Sc. nursing and $3^{\text {rd }}$ year GNM programme and has attended regular classes on antenatal examinations patients in selected nursing institution of Gangtok.

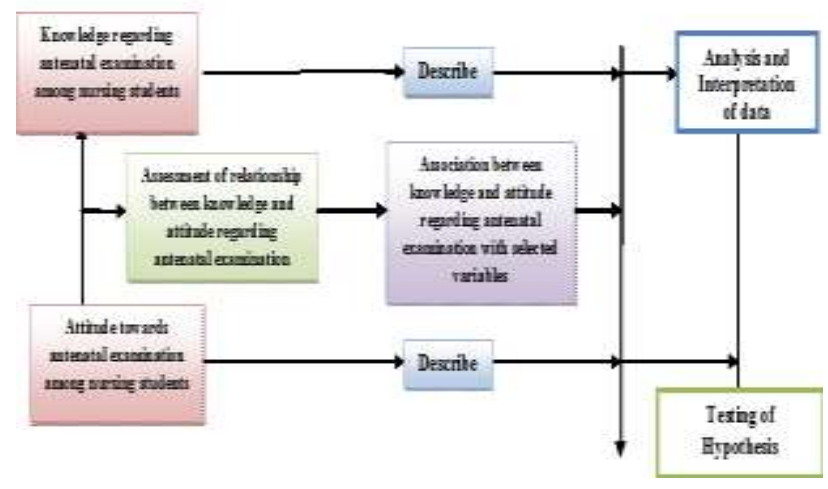

Figure 1: Schematic representation of descriptive co-relational design.

The instrument used for data collection was a structured knowledge questionnaire and structured attitude scale validated by five experts from Department of Obstetrics and Gynecology, and Obstetrics and Gynecological nursing.

The structured knowledge questionnaire contained details of socio-demographic data and questions to assess knowledge regarding antenatal examination. The structured knowledge questionnaire was filled up by the respondents which were tested for its reliability by split half technique and Socio demographic profile by Intrarater method. The structured knowledge questionnaire had two sections. Section I, part A was composed of nine items to collect the information regarding personal characteristics included age in years, marital status, nursing programme currently undergoing, type of institution, previous experience in attending any classes or demonstration on antenatal examination, exposure to mass media related to antenatal examination, clinical posting in OBG ward currently, experience in taking care of antenatal mother, number of times performed antenatal examination. Part B consists of two items to collect information regarding educational profile of nursing students through record review. Section II consisted of thirty items with multiple choice questions. Each correct response was scored 1 to collect the information from nursing students regarding knowledge on antenatal examination.

The reliability of the structured attitude scale was tested by Cronbach's Alpha test. The attitude towards antenatal examination was assessed using scale which included statements on purpose, instruction, preparation, procedure and nurse's responsibility towards antenatal examination using the four point Likert scale.

Ethical permission was sought from institutional ethics committee and informed written consent was taken from all the participants. After explaining the purpose of the study the administrative approval was taken, Self introduction and establishment of rapport with the participants was done to gain their co-operation and after that the nursing students were given the questionnaire.

\section{RESULTS}

\section{Section I: Findings related to demographic data of nursing students at selected nursing institution}

Among the 64 participants, $62.5 \%$ were between $21-23$ years and almost $92.1 \%$ of the nursing students were unmarried. $54.6 \%$ of the nursing students were currently undergoing GNM programme, $26.5 \%$ were undergoing PBBSc nursing programme and $18.75 \%$ were undergoing B.Sc. Nursing. 43.75 of the participants were selected from Vinayka mission Institute, 98.4 have already attended classes and demonstration on antenatal examination and majority of them felt that the classes were adequate.

Information obtained through media regarding antenatal examination was only $19 \%$ in the study. Regarding the number of times they had performed antenatal examination. Nearly equal numbers of participants were having the clinical posting in OBG ward at the time of data collection. $100 \%$ of the participants had provided care to the antenatal women and only $20.3 \%$ of the participants had performed antenatal examination more than twenty times.

Almost $90.6 \%$ of the participants had attended theory classes more than eighty percent allotted whereas only 9 $\%$ attended less than $80 \%$ hour in theory classes. In terms of attending clinical hours, nearly $94.2 \%$ of the participants had attended more than eighty percent in midwifery clinical (Table 1). 
Table 1: Distribution of student nurses from selected nursing institutions in terms of their demographic data $(\mathrm{N}=64)$.

\begin{tabular}{|c|c|c|c|}
\hline \multirow{2}{*}{ Sr. No. } & \multirow{2}{*}{ Demographic Variables } & \multicolumn{2}{|c|}{ Nursing students } \\
\hline & & f & $\%$ \\
\hline \multirow{4}{*}{1.} & Age (in years) & & \\
\hline & $1.118-20$ & 9 & 14 \\
\hline & $1.221-23$ & 40 & 62.5 \\
\hline & 1.323 and above & 15 & 23.4 \\
\hline \multirow{3}{*}{2.} & Marital status & & \\
\hline & 2.1 Unmarried & 5 & 7.8 \\
\hline & 2.2 Married & 59 & 92.1 \\
\hline \multirow{7}{*}{3.} & Nursing programme currently undergoing & & \\
\hline & $3.1 \mathrm{GNM}$ & 35 & 54.6 \\
\hline & 3.2 PBBSc. Nursing & 17 & 26.5 \\
\hline & 3.3 B Sc Nursing & 12 & 18.75 \\
\hline & 3.3.1: If in B Sc Nursing programme mention the year of study & & \\
\hline & 3.3.1.1 $3^{\text {rd }}$ year & 4 & 33.3 \\
\hline & $3.3 .1 .24^{\text {th }}$ year & 8 & 66.6 \\
\hline \multirow{4}{*}{4.} & Mention the name of the School of nursing/College of nursing & & \\
\hline & 4.1 Nursing training centre, STNM hospital & 19 & 29.6 \\
\hline & 4.2 Vinayka mission Institute & 28 & 43.75 \\
\hline & 4.3 Sikkim manipal college of nursing & 17 & 26.5 \\
\hline \multirow{7}{*}{5.} & Do you attend any classes or demonstration on antenatal examination & & \\
\hline & 5.1 Yes & 63 & 98.4 \\
\hline & 5.2 No & 1 & 1.6 \\
\hline & $\begin{array}{l}\text { 5.2.1 If yes, please mention how you feel about the classes or demonstration on } \\
\text { antenatal examination }\end{array}$ & & \\
\hline & 5.2.1.1 Adequate classes or demonstration on antenatal examination & 45 & 70.3 \\
\hline & 5.2.1.2 Need some more classes or demonstration on antenatal examination & 18 & 28.1 \\
\hline & 5.2.1.3 Inadequate classes or demonstration on antenatal examination & 1 & 1.56 \\
\hline \multirow{3}{*}{6.} & $\begin{array}{l}\text { Do you have any exposure to mass media related to antenatal examination } \\
6.1 \text { Yes }\end{array}$ & 12 & 18.75 \\
\hline & $6.2 \mathrm{No}$ & 52 & 81.25 \\
\hline & $\begin{array}{l}\text { 6.1.1 If yes, then specify the type of mass media............................. } \\
6.1 .1 .1 \text { Video }\end{array}$ & 12 & 100 \\
\hline \multirow{3}{*}{7.} & Do you have clinical posting in OBG ward currently & & \\
\hline & 7.1 Yes & 32 & 50 \\
\hline & $7.2 \mathrm{No}$ & 32 & 50 \\
\hline \multirow{3}{*}{8.} & Any previous experience in taking care of antenatal mother & & \\
\hline & $8.1 \mathrm{Yes}$ & 64 & 100 \\
\hline & $8.2 \mathrm{No}$ & - & \\
\hline \multirow{4}{*}{9.} & How many times you have performed antenatal examination & & \\
\hline & $9.1<10$ times & 33 & 51.5 \\
\hline & 9.210 to 20 times & 18 & 28.1 \\
\hline & $9.3>20$ times & 13 & 20.3 \\
\hline
\end{tabular}

Table 2: Nursing student's knowledge related to antenatal examination $(\mathrm{N}=64)$.

\begin{tabular}{|lllllll|}
\hline Variables & Total score & Score range & Mean & Mean \% & Median & Standard deviation \\
\hline $\begin{array}{l}\text { Nursing students knowledge } \\
\text { regarding antenatal examination }\end{array}$ & 1286 & $14-27$ & 20.07 & $66.97 \%$ & 20 & 3.36 \\
\hline
\end{tabular}




\section{Section II: Findings related to knowledge related to antenatal examination among nursing students}

The data presented in Table 2 shows that the total knowledge score of nursing students regarding antenatal examination was 1286 with the score range of 14-27. The mean for knowledge score among nursing students was 20.07 with mean percentage score of $66.97 \%$.The standard deviations for knowledge score among nursing students was 3.36 which shows the scores were deviated (Table 2).

Knowledge regarding the antenatal examination among nursing students was found to be inadequate among the participant. It was also found that only $15.6 \%$ of the participants had adequate knowledge on antenatal examination even though the number of theory hour's attended and total classes and demonstration ratio was quiet high (Figure 2).

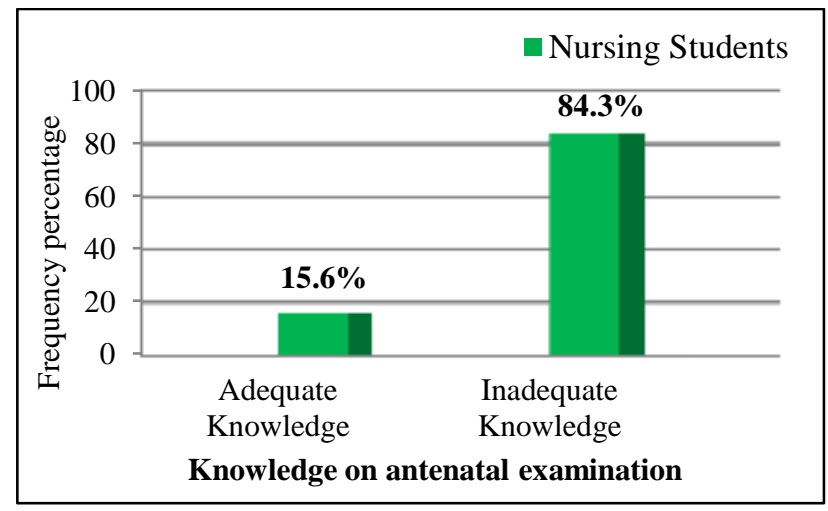

Figure 2: Level of knowledge score.

Section III: Findings related to attitude towards antenatal examination among nursing students.

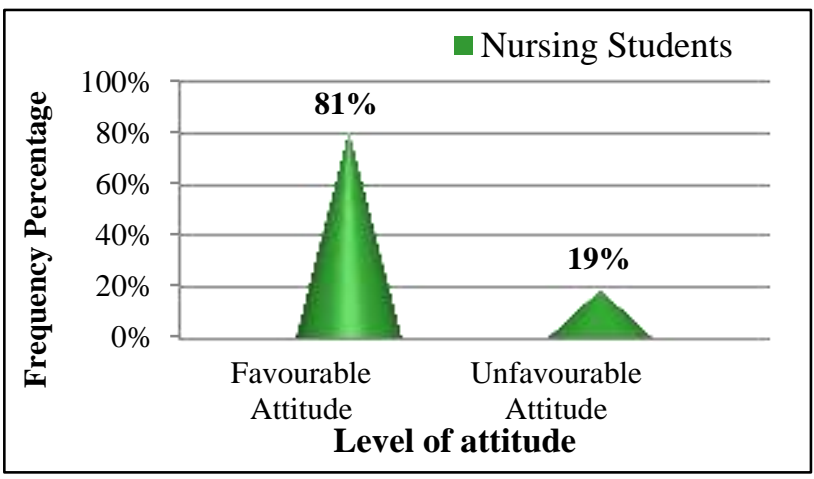

Figure 3: Level of attitude score.

Almost $81 \%$ of the nursing students had favourable attitude towards antenatal examination and $19 \%$ of the nursing students had unfavourable attitude towards antenatal examination (Figure 3).
The data also reveals that the overall score percentage of favourable attitude score towards antenatal examination among nursing students was $89.5 \%$ with the mean of 75.2 and standard deviation of 4.098 whereas for unfavourable attitude score, the score percentage is $19 \%$ with mean of 64.16 and standard deviation of 3.95 . Hence the nursing students were having more favourable attitude towards antenatal examination (Table 3 ).

Table 3: Level of nursing student's attitude towards antenatal examination.

\begin{tabular}{|llllll|}
\hline $\begin{array}{l}\text { Level of } \\
\text { attitude } \\
\text { score }\end{array}$ & $\begin{array}{l}\text { Maximum } \\
\text { score }\end{array}$ & $\begin{array}{l}\text { Score } \\
\%\end{array}$ & Mean & Median & $\begin{array}{l}\text { Standard } \\
\text { deviation }\end{array}$ \\
\hline $\begin{array}{l}\text { Favorable } \\
\text { attitude }\end{array}$ & 3911 & $89.5 \%$ & 75.2 & 75 & 4.098 \\
\hline $\begin{array}{l}\text { Unfavorable } \\
\text { attitude }\end{array}$ & 770 & $19 \%$ & 64.16 & 66 & 3.95 \\
\hline
\end{tabular}

$\mathrm{N}=64$

Section IV: Findings related to relationship between nursing students knowledge and attitude towards antenatal examination at selected nursing institution

The data shows that the estimated value of ' $r$ ' between knowledge and attitude towards antenatal examination is 0.15 which shows no relationship did exist between these two variables. Thus, this indicates that the hypothesis $\mathrm{H}_{1}$ is rejected for nursing students. Hence, it indicates that there is a no relationship between nursing student's knowledge and attitude towards antenatal examination, which established the fact that even though the nursing students had favourable attitude towards antenatal examination but unless it is compounded by good knowledge there will not be a quality care during antenatal examination procedure (Table 4).

Table 4: Relationship between knowledge and attitude towards obstetrical palpation among nursing students.

\begin{tabular}{|llll|}
\hline Variable & Mean & SD & r \\
\cline { 1 - 2 } Knowledge & 20.07 & 3.36 & \multirow{2}{*}{0.15} \\
\cline { 1 - 3 } Attitude & 73.14 & 5.93 & \\
\hline
\end{tabular}

\section{Section V: Findings related to association between nursing student's knowledge regarding antenatal examination with selected variables}

The data reveals that the obtained chi square value for age $(1.95, \mathrm{df}=2)$, exposure to mass media $(0.22, \mathrm{df}=1)$, Number of times performed antenatal examination (3.0561, df=2), and total midwifery hours attended(NA, $\mathrm{df}=2$ ) which was not statistically significant at 0.05 level of significance, therefore there is no association seen with nursing students knowledge with their age, exposure to video on antenatal examination, number of times performed antenatal examination and more hours of theory attended in midwifery. 
Table 5: Association between nursing student's knowledge regarding antenatal examination with selected variables $(\mathrm{N}=64)$.

\begin{tabular}{|c|c|c|c|c|c|c|}
\hline \multirow{2}{*}{ Sr. no } & \multirow{2}{*}{ Selected variables } & \multicolumn{5}{|c|}{ Knowledge score } \\
\hline & & Adequate & Inadequate & df & $\mathbf{x} 2$ & P -value \\
\hline 1 & Age (in years) & & & & & \\
\hline 1.1 & $18-20$ & 6 & 3 & & & \\
\hline 1.2 & $21-23$ & 20 & 20 & 2 & 1.95 & $\mathrm{P}>0.05$ \\
\hline 1.3 & 23 and above & 10 & 5 & & & \\
\hline 2 & Nursing programme currently undergoing & & & & & \\
\hline 2.1 & GNM & 16 & 19 & & & \\
\hline 2.2 & PBBSc. Nursing & 14 & 3 & 2 & $9.07 *$ & $\mathrm{P}<0.05$ \\
\hline 2.3 & B.Sc. Nursing & 6 & 6 & & & \\
\hline 3. & $\begin{array}{l}\text { Do you have any exposure to mass media related to } \\
\text { obstetrical palpation }\end{array}$ & & & & & \\
\hline 3.1 & Yes & 6 & 6 & & & \\
\hline 3.2 & No & 30 & 22 & 1 & 0.22 & $P>0.05$ \\
\hline 4. & $\begin{array}{l}\text { How many times you have performed antenatal } \\
\text { examination }\end{array}$ & & & & & \\
\hline 4.1 & $<10$ times & 16 & 17 & & & \\
\hline 4.2 & 10 to 20 times & 10 & 8 & 2 & 3.056 & $\mathrm{P}>0.05$ \\
\hline 4.3 & $>20$ times & 10 & 3 & & & \\
\hline 5. & $\begin{array}{l}\text { Total midwifery hours attended in theory class till } \\
\text { now as per class attendance register }\end{array}$ & & & & & \\
\hline 5.1 & $<50 \%$ of theory hour & 0 & 5 & & & \\
\hline 5.2 & $50-80 \%$ of theory hour & 0 & 12 & 2 & NA & NA \\
\hline 5.3 & $>80 \%$ of theory hour & 53 & 22 & & & \\
\hline
\end{tabular}

Table 6: Association between nursing student's attitude towards antenatal examination with selected variables $(\mathrm{N}=64)$.

\begin{tabular}{|c|c|c|c|c|c|c|}
\hline \multirow{2}{*}{ Sr. no } & \multirow{2}{*}{ Selected variables } & \multicolumn{5}{|c|}{ Attitude score } \\
\hline & & Favorable & Unfavorable & df & $x 2$ & P -value \\
\hline 1 & Age (in years) & & & & & \\
\hline 1.1 & $18-20$ & 5 & 4 & & & \\
\hline 1.2 & $21-23$ & 20 & 20 & 2 & 4.34 & $P>0.05$ \\
\hline 1.3 & 23 and above & 11 & 4 & & & \\
\hline 2 & Nursing programme currently undergoing & & & & & \\
\hline 2.1 & GNM & 19 & 16 & & & \\
\hline 2.2 & PBBSc. Nursing & 12 & 5 & 2 & 2.48 & $\mathrm{P}>0.05$ \\
\hline 2.3 & B Sc Nursing & 5 & 7 & & & \\
\hline 3. & $\begin{array}{l}\text { Do you have any exposure to mass media related to } \\
\text { obstetrical palpation }\end{array}$ & & & & & \\
\hline 3.1 & Yes & 5 & 7 & 1 & 1.26 & $\mathrm{P}>0.05$ \\
\hline 3.2 & No & 31 & 21 & & & \\
\hline 4. & $\begin{array}{l}\text { How many times you have performed antenatal } \\
\text { examination }\end{array}$ & & & & & \\
\hline 4.1 & $<10$ times & 15 & 18 & 2 & 720 & $P<005$ \\
\hline 4.2 & 10 to 20 times & 10 & 8 & 2 & 1.29 & $P<0.05$ \\
\hline 4.3 & $>20$ times & 11 & 2 & & & \\
\hline 5. & $\begin{array}{l}\text { Total midwifery hours attended in theory class till now } \\
\text { as per class attendance register }\end{array}$ & & & & & \\
\hline 5.1 & $<50 \%$ of theory hour & 2 & 3 & 2 & & \\
\hline 5.2 & $50-80 \%$ of theory hour & 3 & 9 & 2 & 1.04 & $P<0.05$ \\
\hline 5.3 & $>80 \%$ of theory hour & 31 & 16 & & & \\
\hline
\end{tabular}


The table also reveals that the obtained chi square value for nursing programme currently undergoing by the nursing students $\left(9.07^{*}, \mathrm{df}=2\right)$ was significant at 0.05 level of significance. Hence the knowledge of nursing students was found to be dependent upon the type of nursing programme currently undergoing by the nursing students (Table 5).

\section{Section VI: Findings related to association between nursing student's attitude towards antenatal examination with selected variables.}

The data reveals that the obtained chi square value for age $(4.34, \mathrm{df}=2)$, nursing programme currently undergoing $(2.48, \mathrm{df}=1)$ and exposure to mass media on antenatal examination $(1.26, \mathrm{df}=2)$ was not found statistically significant at 0.05 level of significance, therefore there is no association seen with nursing students attitude with their age, nursing programme currently undergoing, and exposure to video on antenatal examination.

The table also reveals that the obtained chi square value for number of times performed antenatal examination by the nursing students $\left(7.29^{*}, \mathrm{df}=2\right)$ and total midwifery hours attended $(7.04 *, \mathrm{df}=2)$ was significant at 0.05 level of significance. Hence the attitude of nursing students was found to be dependent upon the number of times nursing students performed antenatal examination and number of hours they attended Midwifery (Table 6).

\section{DISCUSSION}

The present study also showed that the knowledge regarding the antenatal examination among nursing students was found to be inadequate. It was also found that only $15.6 \%$ of the participants had adequate knowledge on antenatal examination even though the number of theory hour's attended and total classes and demonstration ratio was quiet high.

The findings of the present study was consistent with the findings of the study conducted by Fungai Muzeya who conducted a quantitative, descriptive, cross-sectional research to assess the knowledge, attitudes and practices of nurse-midwives related to obstetric care at ThabaTseka, Lesotho among 45 nurse-midwives. ${ }^{10}$ The findings revealed that nurse-midwives had mean knowledge score of $10.5(80.7 \%)$ out of a possible 13 (Standard Deviation (SD) 1.31) on obstetric care issues. However, the majority of nurse-midwives $(n=28,62.2 \%)$ did not have knowledge on antenatal care. The mean scores on practice were $34.5(86.2 \%)$ against a possible 40 (SD 5.43) for antenatal care, $39.2(89 \%)$ against a possible of 44 (SD 4.66) and $22.4(93.3 \%)$ against a possible of 24 (SD 2.18) for postnatal care.

The findings were similar with the study conducted by Sumol. C. Abraham where overall knowledge of nursing students regarding antenatal care was very less. ${ }^{9}$ Most of the respondents $97(80.83 \%)$ scored less than $45 \%$ that is they had low level knowledge, $19(15.83 \%)$ had moderate knowledge with scores between $45-60 \%$ and only 4 $(3.33 \%)$ respondents scored more than $60 \%$ i.e. high level of knowledge regarding Antenatal care.

The findings of the present study showed no significant difference in knowledge level of nursing students regarding antenatal examination as far the exposure to mass media is concerned $(x 2=0.22, \mathrm{P}>0.05)$ The findings was found consistent with the findings of the study conducted by Scaria TM, Valsaraj PB, Pias M who found that pretest knowledge of nursing students regarding antenatal examination were independent of their previous experience, previous knowledge and exposure to mass media on antenatal examination. ${ }^{5}$

The findings of the present study also reveals that almost $81 \%$ of the nursing students had favourable attitude towards antenatal examination with overall score percentage of $89.5 \%$ whereas $19 \%$ had unfavourable attitude towards antenatal examination with score percentage of $19 \%$.

The findings of the present study was consistent with the findings of the study conducted by Fungai Muzeya who conducted a quantitative, descriptive, cross-sectional research to assess the knowledge, attitudes and practices of nurse-midwives related to obstetric care at ThabaTseka, Lesotho among 45 nurse-midwives. ${ }^{11}$ The findings revealed that nurse-midwives had positive attitudes towards obstetric care practices with mean score for attitudes was $23.4(86.7 \%)$ against a possible score of 27 (SD 3.02).

\section{Recommendation}

A similar study can be replicated on a large sample, in order to validate the findings and make generalizations. A comparative study can be conducted between ANM students, GNM students, PBBSc students and B.Sc. Nursing students by involving larger sample. An experimental study can be conducted to find out the effectiveness of a new teaching strategy regarding Antenatal examination. A study can be replicated on ANM'S, LHV and Staff Nurses in order to find out their knowledge level and attitude with which they are rendering their services.

\section{CONCLUSION}

Though the theory classes and hour are quiet high for the nursing students but their scores was very less with regard to knowledge. This might have been due to their eight hours clinical posting in various specialty areas and lack of interest for the subject since there is no university examination for the third year B.Sc. Nursing for this academic year and for fourth year there is no theory class for this academic year. 


\section{ACKNOWLEDGMENT}

The researcher thanks all the participants of the study for their kind cooperation.

Funding: No funding sources

Conflict of interest: None declared

Ethical approval: The study was approved by the Institutional Ethics Committee

\section{REFERENCES}

1. World Bank data. http://www.data.worldbank.org/indicator.SHSTA.M MRT.

2. Millennium development goals-India country report 2015. Report from Ministry of Statistics and Programme Implementation. Government of India.www.mospi.nic.in.

3. World Health Organization. Life tables for WHO member states. 2010. http://www.who.int/healthinfo/statistics/mortalitylife tables/en/

4. Ojong IN, Uga AL, Chiotu CN. Knowledge and attitude of pregnant women towards focused ante natal care services in university of calabar teaching hospital, calabar, cross river state, Nigeria. March Retrieved from www.eajournals.org. 2015;1(1):1423.

5. Scaria TM, Valsaraj PB, Pias M. The effectiveness of Video Teaching over Lecture Cum Demonstration in Improving Knowledge and Skill, of Nursing Students on Antenatal Examination. International Journal of Nursing Education. January 2013;5(1):228-30.

6. Mohsen MM, El-Abbassy AA. OSCE tool for Improving B.Sc. Nursing Students' Antenatal
Examination. Journal of Nursing and Health Science. 2015;4(6).

7. Pamela RJ, Sandy R, Toni MC. A comparison of student-centered versus traditional methods of teaching basic nursing skills in a learning laboratory. Nursing Education Perspectives. 2002;23(1):14-1.

8. Cunningham FG, Leveno MD, Bloom S, Hauth JC, Gilstrap L, Wenstrom K. Normal Labour and Delivery. Williams Obstetrics. 2009. $22^{\text {nd }}$ Edition ed. London: McGraw-Hill; 2008:409-42. Accessed January 2, 2014.

9. Abraham SC. Descriptive study to assess the knowledge regarding Antenatal care among BSC Nursing students of selected nursing colleges of Udaipur city with a view to develop an information Booklet. International Journal of Research. 2015;2(3):518-26. Retrieved from http://internationaljournalofresearch.org/

10. Puri R. Knowledge, Attitudes and Practices of Obstetric Care Providers in Bugesera District, Rwanda. Online published thesis submitted in partial fulfillment of the requirements for the degree of Master in Science in the Duke Global Health Institute in the Graduate School of Duke University, 2011.

11. Muzeya F. Knowledge, attitudes and practices of nurse-midwives related to obstetric care at ThabaTseka district in Lesotho. Unpublished Master of Public Health thesis submitted to University of South Africa. June 2015.

Cite this article as: Devi B, Khandelwal B, Das M. Analysis of knowledge and attitude regarding antenatal examination among nursing students in Sikkim - a descriptive co-relational study. Int J Reprod Contracept Obstet Gynecol 2016;5:3871-8. 